\title{
UAV-BASED AUTOMATIC TREE GROWTH MEASUREMENT FOR BIOMASS ESTIMATION
}

\author{
M. Karpina*, M. Jarząbek-Rychard, P. Tymków, A. Borkowski
}

Institute of Geodesy and Geoinformatics, Wroclaw University of Environmental and Life Science, Poland - (mateusz.karpina, malgorzata.jarzabek-rychard, przemyslaw.tymkow, andrzej.borkowski)@igig.up.wroc.pl

\section{Commission VIII, WG VIII/7}

KEY WORDS: UAV, point cloud, biomass estimation, tree height

\begin{abstract}
:
Manual in-situ measurements of geometric tree parameters for the biomass volume estimation are time-consuming and economically non-effective. Photogrammetric techniques can be deployed in order to automate the measurement procedure. The purpose of the presented work is an automatic tree growth estimation based on Unmanned Aircraft Vehicle (UAV) imagery. The experiment was conducted in an agriculture test field with scots pine canopies. The data was collected using a Leica Aibotix X6V2 platform equipped with a Nikon D800 camera. Reference geometric parameters of selected sample plants were measured manually each week. In situ measurements were correlated with the UAV data acquisition. The correlation aimed at the investigation of optimal conditions for a flight and parameter settings for image acquisition.

The collected images are processed in a state of the art tool resulting in a generation of dense 3D point clouds. The algorithm is developed in order to estimate geometric tree parameters from 3D points. Stem positions and tree tops are identified automatically in a cross section, followed by the calculation of tree heights. The automatically derived height values are compared to the reference measurements performed manually. The comparison allows for the evaluation of automatic growth estimation process. The accuracy achieved using UAV photogrammetry for tree heights estimation is about $5 \mathrm{~cm}$.
\end{abstract}

\section{INTRODUCTION}

Effective management of biogas production requires precise estimation of a produced biomass volume. Biomass monitoring is crucial for the decision process related to fertilization, irrigation and use of plant protection products. Such monitoring is needed in order to increase the crop and improve its quality (Rosell and Sanz, 2012). The measurements related to biomass volume assessment can be performed directly in situ or remotely. Within direct measurements we can distinguish destructive and non-destructive procedures. The destructive measurements allow for achievement of the most reliable results. Unfortunately, the measured plant has to be destroyed during the measurement process, which is not always possible. The volume of the biomass can be also estimated based on geometric parameters of trees, e.g. height or stem diameter. Manual measurements performed directly on plants are timeconsuming and often difficult. Moreover, the survey has to be regularly repeated during a growth process.

Remote measurements allow for the acquisition of large amount of data in a relatively short time. The remote measurements techniques are mostly represented by remote sensing analyses, especially multispectral ones. The analysis are frequently used to investigate physical and chemical properties of plants. Recently, also methods based on 3D point clouds analyses became popular. Airborne laser scanning (ALS) is commonly used in forestry for large area measurements. Eysn et al. (2015) present results of a benchmark that compares various single tree detection methods performed on ALS data. Most of the described methods use rasterized CHM. Vega et al. (2014) present PTree algorithm, which is a $3 \mathrm{D}$ point based method for the forest tree extraction. The achieved detection performance is about $82 \%$. Other methods are focused on the extraction of geometric parameters of trees. The parameters include stand height, tree height, and foliage profiles (Coops et al., 2007). Edson and Wing (2011) compare software packages that compute tree height and stem location, followed by biomass estimation.

Low resolution of ALS data may be not sufficient in precision assessment of growth and biomass volume in small areas. In such cases terrestrial laser scanning (TLS) provides better accuracy. TLS allows for 3D mapping of tree parts that are well visible from the ground level. Such parts are stem, branches and lower elements of crown. The research focuses on its detection and measuring. Moskal and Zheng (2011) describe point cloud slicing algorithm for the assessment of tree stem diameter at breast height $(\mathrm{DBH})$, tree height, basal area, and volume. The resulted RMSE for DBH and tree height was $9.2 \mathrm{~cm}$ and $0.75 \mathrm{~m}$ respectively. Olofsson et al. (2014) use for that purpose RANSAC algorithm.

Dynamic evolution of UAV systems enables to join advantages of airborne surveying with accuracy and resolution of terrestrial methods (Colomina and Molina, 2014; Nex and Remondino, 2013; Siebert and Teizer, 2014). UAVs became useful in. crop monitoring for precise agriculture and forestry. Bendig et al. (2014) estimates biomass of crops using photos taken by consumer-grade RGB camera mounted on a small octocopter. Other researchers use multispectral cameras, e.g. near-infrared in addition to RGB (Vega et al., 2015). Tree geometric parameters are also estimated from UAV collected data in orchards (Díaz-Varela et al., 2015; Torres-Sánchez et al., 2015).

\footnotetext{
* Corresponding author
} 
As shown in the studies presented above it is possible to use with UAV platforms almost the same sensor types as on airplane. The sensors are only smaller and lighter.

Biomass volume can be assessed as a function of plant geometric parameters, e.g. height. Therefore. height measurements are important in order to estimate biomass volume increase over time. The purpose of this work, thus, is to investigate and verify the method of tree height estimation for scots pine (pinus sylvestris). The study focuses on the automatic processing of data collected repeatedly in the same area. Close range images taken from UAV are used in order to achieve high accuracy measurements.

\section{MATERIALS AND METHODS}

\subsection{Data acquisition}

The research was conducted in a test field in Agro and Hydrometeorology Observatory of Wroclaw University of Environmental and Life Sciences (Poland). 138 pieces of scots pine (pinus sylvestris) were planted in a regular grid in the rectangular test field of size $18 \mathrm{~m} \times 8 \mathrm{~m}$ (Figure 1). During growth phase the height of previously selected trees was measured manually once a week. The collected data were used as reference values.
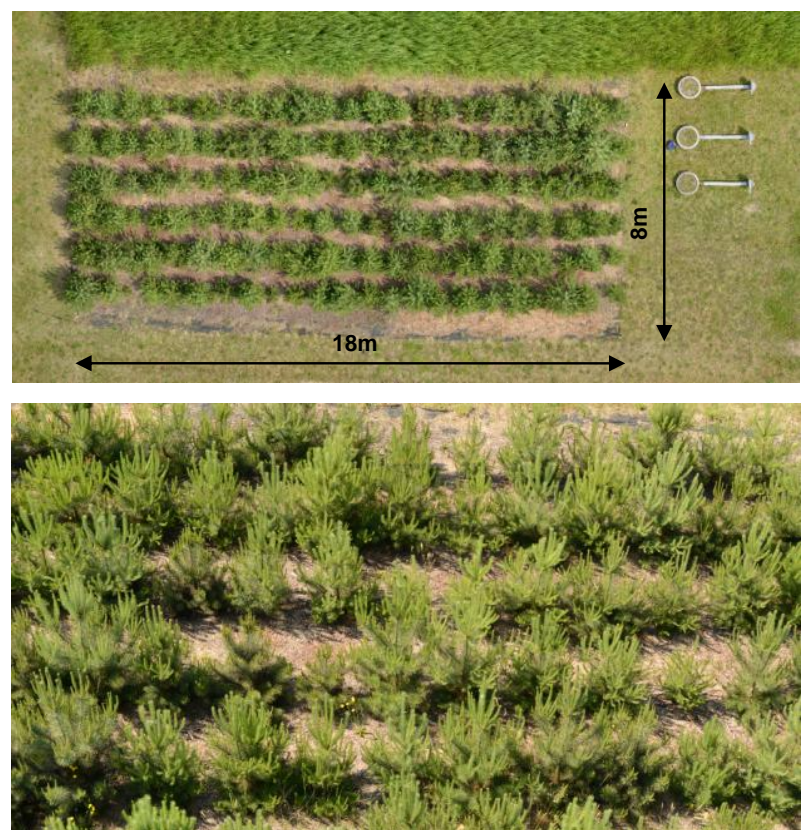

Figure 1. Ortophoto of study area (top); photo of measured plants (bottom)

The images were acquired using Leica Aibotix X6V2 UAV platform (Figure 2). The Aibotix X6V2 is a multi rotor type UAV equipped with 6 electric motors (hexacopter). Its maximum takeoff weight (MTOM) is $6.6 \mathrm{~kg}$, including $2 \mathrm{~kg}$ payload. Automatic pilot allows for execution of prepared flight plans. The photos were taken with Nikon D800, which is a full frame digital single lens reflex camera (DSLR) with sensor size of $35.9 \mathrm{~mm} \times 24 \mathrm{~mm}$ and 36 megapixel resolution $(7360 \mathrm{px} \times$ 4912px). The camera was equipped with AF-S Nikkor $50 \mathrm{~mm}$ f/1.4G lens.

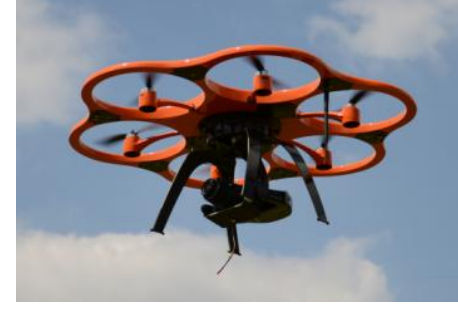

Figure 2. Aibotix X6V2 UAV with Nikon camera

Flight missions were planned for two types of photographs: vertical and oblique. Vertical photos were taken at the altitude of $13 \mathrm{~m}$ above ground with $60 \%$ side and $80 \%$ forward overlap. Altitude for oblique images was $15 \mathrm{~m}$ and vertical angle $45^{\circ}$, forward overlap $65 \%$ and side overlap $90 \%$. The camera was triggered every 2 seconds. Ground control points were located around the test field. Point positions were measured using GNSS RTK techniques.

\subsection{Processing}

Figure 3 presents the proposed workflow for the tree height measurement. The process starts with image acquisition. In the next step dense 3D point cloud is generated using Agisoft Photoscan software. Finally, the point cloud is classified into ground and non-ground points (Figure 4).

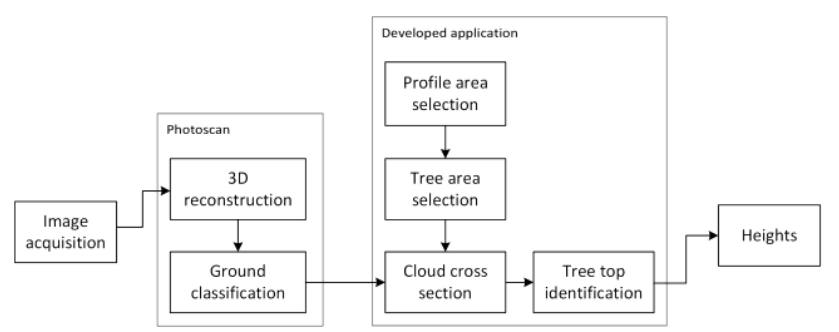

Figure 3. Workflow diagram
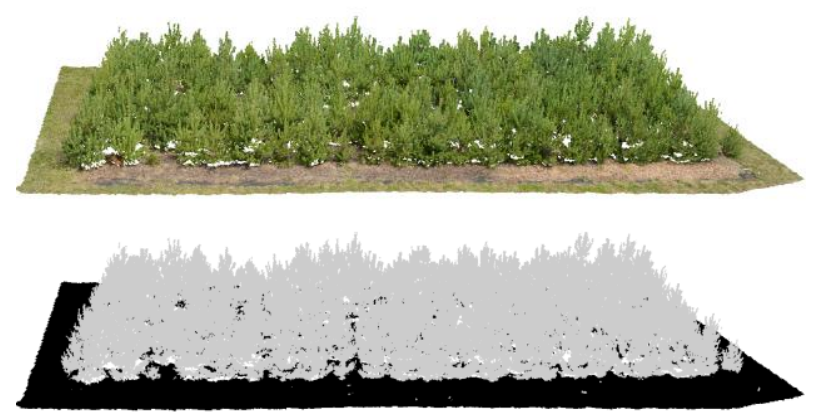

Figure 4. Generated point cloud (top) and ground classification (bottom)

Plant heights are measured on the prepared 3D data. Measurements are performed on a cross section of point cloud that contains one row of trees. For this purpose cross section areas have to be manually defined. Then, the range containing the measured tree has to be selected in a cross section. These manual steps needs to be performed only once for a measured area. Each subsequent measurements will reuse selected areas.

Tree height is calculated as a difference between maximum point $\mathrm{Z}$ coordinate and average $\mathrm{Z}$ coordinate of ground points surrounding the tree:

$$
H=\operatorname{MaxZ}(\text { Points })-A v g Z(\text { Ground })
$$




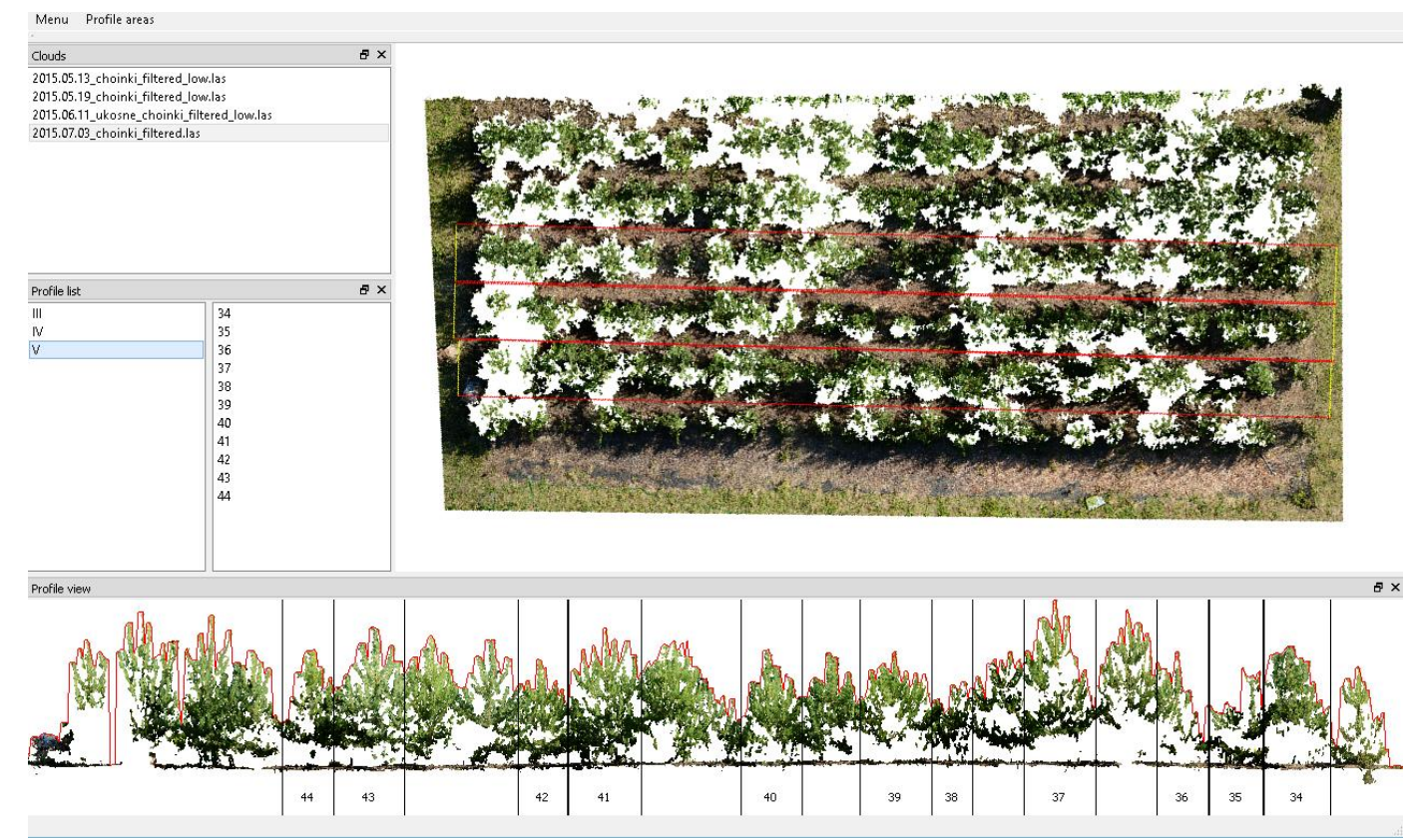

Figure 5. Graphical user interface of tree height measurement application

where $\mathrm{H}-$ tree height

Points - Set of points cut by tree area

Ground - Ground class points from the same tree area

Height measurement algorithm and profile area selection was implemented as a GUI application. The code was written in $\mathrm{C}++$ language using LASlib library, Eigen and Qt for graphical user interface. Main window of GUI (Figure 5) was divided into following parts: list of input LAS-files, list of profile areas with tree list, cross section view and main view of a point cloud. Although the cross sections are presented as $2 \mathrm{D}$ raster, the points remains internally stored as $3 \mathrm{D}$ (the points are trimmed and transformed to selected are).

\section{DISCUSSION}

Measurements of the tree height, which is the key parameter for biomass increase assessment, is affected by certain inaccuracy. This accuracy was estimated by comparing the measurement results for three measuring periods. UAV measurements were compared with the reference data (direct measurements performed on the same day). Differences between UAV and reference heights as well as basic statistics are listed in Table 1. For the first measurement root mean square error (RMSE) was equal to $32 \mathrm{~cm}$. The analysis of achieved data and measurement results allowed for a correction of shooting parameters during later flights. This resulted in a RMSE of approximately $5 \mathrm{~cm}$ for the last measurement.

Height differences in last measurement was approximately 24 $\mathrm{cm}$. More detailed analysis of differences is presented in histograms (Figure 6). The figure shows the number of measurements divided into classes according to difference value. Class division was done by equal interval method. As shown in the charts, the smallest dispersion was achieved in the last measurement.

Qualitative analysis of the data leads to the conclusion that the accuracy of height measurement is highly depended on the quality of a generated $3 \mathrm{D}$ point cloud. A common situation is a lack of parts of plants in a point cloud. This may be treated as a gross error. In order to increase measurement accuracy the algorithm may be improved by filtering out worse imaged trees. Such trees will be labeled and processed manually.

Another issue is lack of ground points directly under the tree crown, which effects in inaccuracy of estimation of a ground level. Lack of ground points may be solved by adoption of DTM as a constant ground reference model.

\begin{tabular}{|c|ccc|}
\cline { 2 - 4 } \multicolumn{1}{c|}{} & \multicolumn{3}{c|}{ Height difference (UAV - REF) [m] } \\
\hline Tree label & 15.05 .2015 & 26.06 .2015 & 3.07 .2015 \\
\hline 23 & 0.113 & -0.031 & -0.030 \\
24 & -0.239 & -0.350 & -0.019 \\
25 & -0.029 & -0.117 & -0.015 \\
26 & 0.206 & 0.018 & -0.020 \\
28 & -0.129 & -0.112 & -0.022 \\
29 & 0.049 & -0.088 & -0.013 \\
30 & 0.271 & 0.007 & -0.033 \\
31 & 0.007 & -0.012 & -0.047 \\
32 & 0.420 & -0.008 & -0.025 \\
33 & 0.407 & 0.009 & -0.054 \\
34 & 0.187 & 0.004 & -0.039 \\
35 & 0.173 & -0.046 & -0.067 \\
36 & 0.155 & -0.103 & -0.096 \\
37 & 0.498 & -0.004 & -0.005 \\
38 & 0.013 & 0.137 & -0.048 \\
39 & 0.230 & 0.003 & 0.083 \\
40 & 0.066 & -0.019 & -0.028 \\
41 & 0.058 & -0.018 & -0.031 \\
42 & 0.399 & -0.003 & 0.140 \\
43 & 0.590 & -0.023 & -0.004 \\
44 & 0.784 & 0.005 & -0.028 \\
max [m] & 0.447 & -0.008 & -0.042 \\
min [m] & 0.784 & 0.137 & 0.140 \\
sigma [m] & -0.239 & -0.350 & -0.096 \\
mean [m] & 0.246 & 0.089 & 0.048 \\
RMSE [m] & 0.213 & -0.035 & -0.020 \\
\hline & 0.321 & 0.093 & 0.051 \\
\hline
\end{tabular}

Table 1. Height differences and statistics 

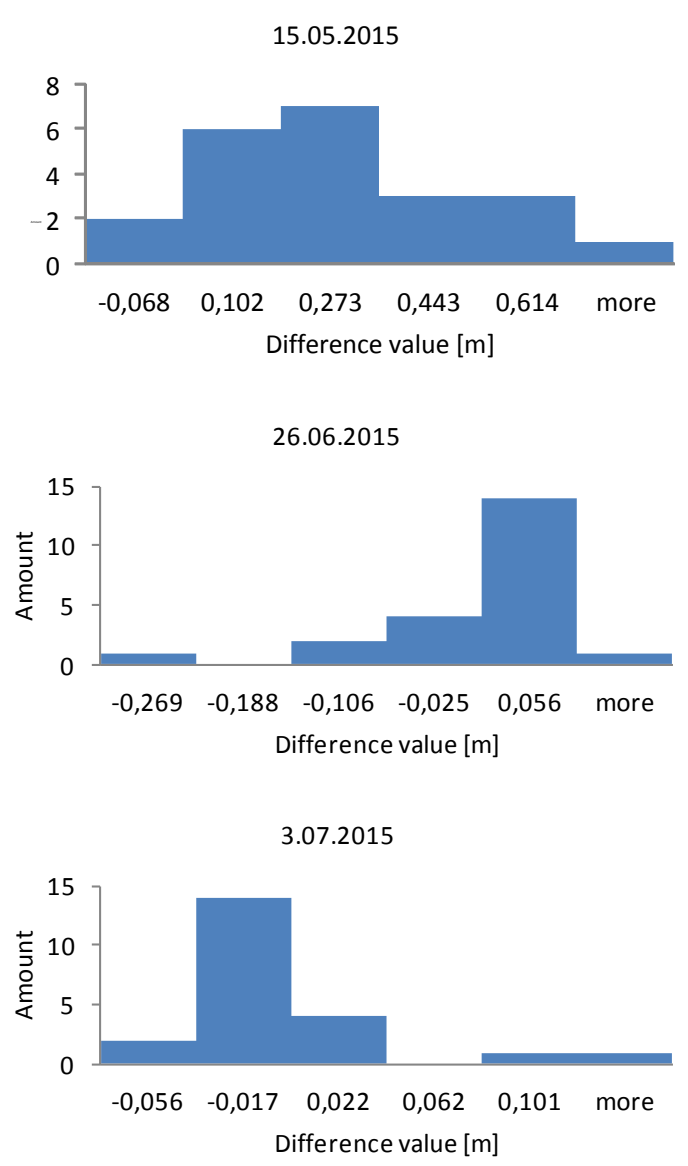

Figure 6. Histograms of calculated height differences

\section{CONCLUSIONS}

In this study, the first results of the remote monitoring of the tree growth are presented. The proposed method of tree growth estimation is based height measurements on point clouds generated from UAV imagery. The achieved accuracy is about $5 \mathrm{~cm}$. This result is promising and indicates on the feasibility of UAV application in the biomass estimation. However, the proposed method should be improved. For this reason we will try to determine optimal data acquisition conditions and we will combine various UAV sensors in order to increase accuracy of three height determination.

\section{ACKNOWLEDGEMENTS}

The authors acknowledge prof. Andrzej Żyromski and dr Małgorzata Biniak-Piróg from the Institute of Environmental Protection and Development, Wroclaw University of Environmental and Life Sciences for providing the reference data.

\section{REFERENCES}

Bendig, J., Bolten, A., Bennertz, S., Broscheit, J., Eichfuss, S., Bareth, G., 2014. Estimating Biomass of Barley Using Crop Surface Models (CSMs) Derived from UAV-Based RGB Imaging. Remote Sens. 6, 10395-10412. doi:10.3390/rs61110395

Colomina, I., Molina, P., 2014. Unmanned aerial systems for photogrammetry and remote sensing: A review. ISPRS J.
Photogramm. Remote Sens. 92, 79-97. doi:10.1016/j.isprsjprs.2014.02.013

Coops, N.C., Hilker, T., Wulder, M.A., St-Onge, B., Newnham, G., Siggins, A., Trofymow, J.A. (Tony), 2007. Estimating canopy structure of Douglas-fir forest stands from discretereturn LiDAR. Trees 21, 295-310. doi:10.1007/s00468-0060119-6

Díaz-Varela, R.A., de la Rosa, R., León, L., Zarco-Tejada, P.J., 2015. High-Resolution Airborne UAV Imagery to Assess Olive Tree Crown Parameters Using 3D Photo Reconstruction: Application in Breeding Trials. Remote Sens. 7, 4213-4232. doi:10.3390/rs70404213

Edson, C., Wing, M.G., 2011. Airborne Light Detection and Ranging (LiDAR) for Individual Tree Stem Location, Height, and Biomass Measurements. Remote Sens. 3, 2494-2528. doi:10.3390/rs3112494

Eysn, L., Hollaus, M., Lindberg, E., Berger, F., Monnet, J.-M., Dalponte, M., Kobal, M., Pellegrini, M., Lingua, E., Mongus, D., Pfeifer, N., 2015. A Benchmark of Lidar-Based Single Tree Detection Methods Using Heterogeneous Forest Data from the Alpine Space. Forests 6, 1721-1747. doi:10.3390/f6051721

Moskal, L.M., Zheng, G., 2011. Retrieving Forest Inventory Variables with Terrestrial Laser Scanning (TLS) in Urban Heterogeneous Forest. Remote Sens. 4, 1-20. doi:10.3390/rs4010001

Nex, F., Remondino, F., 2013. UAV for 3D mapping applications: a review. Appl. Geomat. 6, 1-15. doi:10.1007/s12518-013-0120-x

Olofsson, K., Holmgren, J., Olsson, H., 2014. Tree Stem and Height Measurements using Terrestrial Laser Scanning and the RANSAC Algorithm. Remote Sens. 6, 4323-4344. doi:10.3390/rs6054323

Rosell, J.R., Sanz, R., 2012. A review of methods and applications of the geometric characterization of tree crops in agricultural activities. Comput. Electron. Agric. 81, 124-141. doi:10.1016/j.compag.2011.09.007

Siebert, S., Teizer, J., 2014. Mobile 3D mapping for surveying earthwork projects using an Unmanned Aerial Vehicle (UAV) system. Autom. Constr. 41, 1-14. doi:10.1016/j.autcon.2014.01.004

Torres-Sánchez, J., López-Granados, F., Serrano, N., Arquero, O., Peña, J.M., 2015. High-Throughput 3-D Monitoring of Agricultural-Tree Plantations with Unmanned Aerial Vehicle (UAV) Technology. PLOS ONE 10, e0130479. doi:10.1371/journal.pone.0130479

Vega, C., Hamrouni, A., El Mokhtari, S., Morel, J., Bock, J., Renaud, J.-P., Bouvier, M., Durrieu, S., 2014. PTrees: A pointbased approach to forest tree extraction from lidar data. Int. J. Appl. Earth Obs. Geoinformation 33, 98-108. doi:10.1016/j.jag.2014.05.001

Vega, F.A., Ramírez, F.C., Saiz, M.P., Rosúa, F.O., 2015. Multi-temporal imaging using an unmanned aerial vehicle for monitoring a sunflower crop. Biosyst. Eng. 132, 19-27. doi:10.1016/j.biosystemseng.2015.01.008 